\title{
Pathology: Classification and Immunoprofile
}

\author{
Annika Blank - Anja Schmitt • Aurel Perren \\ Institute of Pathology, University of Bern, Switzerland
}

\begin{abstract}
The classification of neuroendocrine neoplasms (NENs) has been evolving steadily over the last decades. Important prognostic factors of NENs are their proliferative activity and presence/absence of necrosis. These factors are reported in NENs of all body sites; however, the terminology as well as the exact rules of classification differ according to the location of the primary tumor. Only in gastroenteropancreatic (GEP) NENs a formal grading is performed. This grading is based on proliferation assessed by the mitotic count and/or Ki-67 proliferation index. In the lung, NEN grading is an intrinsic part of the tumor designation with typical carcinoids corresponding to neuroendocrine tumor (NET) G1 and atypical carcinoids to NET G2; however, the presence or absence of necrotic foci is as important as proliferation for the differentiation between typical and atypical carcinoids. Immunohistochemical markers can be used to demonstrate neuroendocrine differentiation. Synaptophysin and chromogranin A are, to date, the most reliable and most commonly used for this purpose. Beyond this, other markers can be helpful, for example in the situation of a NET metastasis of unknown primary, where a hormonal profile or a panel of transcription factors can give hints to the primary site. Many immunohistochemical markers have been shown to correlate with prognosis but are not used in clinical practice, for example cytokeratin 19 and KIT expression in pancreatic NETs. There is no predictive biomarker in use, with the exception of somatostatin receptor (SSTR) 2 expression for predicting the amenability of a tumor to in vivo SSTR targeting for imaging or therapy.
\end{abstract}

○ 2015 S. Karger AG, Basel

\section{Classification of Neuroendocrine Neoplasms in the Gastroenteropancreatic System}

The histological diagnosis of neuroendocrine neoplasms (NENs) is based on morphological criteria and is confirmed by immunohistochemical staining. NENs are subdivided into well-differentiated tumors and poorly differentiated carcinomas, according to their histomorphologic appearance. 
Table 1. Grading according to Rindi et al. [7] and UICC/AJCC 2010

\begin{tabular}{lll}
\hline Grade & Mitotic count $\left(2 \mathrm{~mm}^{2}\right)$ & Ki-67, \% \\
\hline G1 & $<2$ & $\leq 2$ \\
G2 & $2-20$ & $3-20$ \\
G3 & $>20$ & $>20$ \\
\hline
\end{tabular}

\section{Well-Differentiated Neuroendocrine Tumors}

Well-differentiated neuroendocrine tumors (NETs) are usually solitary, well-demarcated tumors which harbor a broad spectrum of possible growth patterns. Most commonly they show a solid, trabecular, gyriform or glandular pattern; less frequently they have a spindle cell, angiomatous, papillary or rhabdoid morphology $[1,2]$. Occasionally, pancreatic NETs display cystic changes [3, 4].

The tumor cells are usually monomorphous with round to oval, centrally located nuclei and finely dispersed chromatin (so called 'salt and pepper'); however, they can also exhibit a striking variation in nuclear size and chromatin density. The cytoplasm has a granular, often eosinophilic aspect. Clear cell changes occur due to the storage of lipids [5].

The extent of the stromal component is very variable. The grading of gastroenteropancreatic (GEP)-NETs is either based on the mitotic count or on immunohistochemistry for Ki-67 [1,6]. Mitoses are counted on hematoxylin and eosin (HE) staining in an area of $2 \mathrm{~mm}^{2}$ in the area of highest mitotic count. The recommended Ki-67 antibody for assessment of the proliferation index is the clone MIB1. The proliferative index is determined in 2,000 tumor cells in the area of highest density of positive nuclear staining (the 'hot spot') with at least a 400-fold magnification (table 1).

Well-differentiated NETs are subdivided into two subgroups according to their proliferative activity. G1 NETs have a low proliferative activity $\left(<2\right.$ mitoses/2 $\mathrm{mm}^{2}$; MIB1 $\leq 2 \%$ ) and an indolent clinical course with a prolonged survival. G2 NETs have an intermediate proliferative activity ( $\geq 2-20$ mitoses/2 $\mathrm{mm}^{2}$; MIB1 3-20\%) and adverse outcome in comparison to G1 tumors, although they also have a prolonged clinical course $[7,8]$. From a biological point of view, the actual strict separation into two prognostic groups can be questioned and in fact it seems that there might be a more gradual increase of the risk of malignancy with increase of the Ki-67 index [9].

\section{Poorly Differentiated Neuroendocrine Carcinomas}

Poorly differentiated neuroendocrine carcinomas (NECs) are characterized by a high degree of pleomorphism, irregular nuclei and hyperchromasia. The growth pattern is predominantly sheet-like or diffuse. Mitoses are frequently found as well as extensive geographic necrosis [5].

GEP-NECs $[1,6]$ have frequent mitoses, by definition more than 20 per $2 \mathrm{~mm}^{2}$, and/or high proliferative indices of $>20 \%$, although most carcinomas exceed these 
thresholds by far. They are further subdivided into small and large cell NECs according to the size of their nuclei. Large cells are defined by a nuclear size of $>3$ lymphocytes. GEP-NECs are high-grade carcinomas with a rapid progression and short overall survival.

\section{Mixed Adenoneuroendocrine Carcinoma}

A mixed adenoneuroendocrine carcinoma (MANEC) is a neoplasm consisting of an exocrine and an endocrine component. By definition, each component should comprise at least $30 \%$ of the tumor volume, otherwise the tumor is referred to as adenocarcinoma with partial neuroendocrine differentiation [10]. An adenocarcinoma component is by far the most common for the exocrine element. An exception is represented by esophageal and anal MANEC, in which a squamous differentiation can also be found [11]. Each component should be graded separately, with the adenocarcinoma according to the guidelines for conventional adenocarcinomas of the affected organ, whereas the neuroendocrine component is graded according to the guidelines for GEP-NETs [11].

\section{TNM Staging System}

For GEP-NENs there are currently two staging systems in use, namely the UICC and the European Neuroendocrine Tumor Society (ENETS) systems [12, 13]. With the exception of pancreatic and appendiceal NETs, both systems are identical. While there are no data available yet for appendiceal NETs, for pancreatic NETs the ENETS staging system has repeatedly been shown to be superior in discriminating between prognostically meaningful different stages [7, 14-17]. To ensure the comparability of data and avoid confusion, both staging systems should be reported [18]

\section{Classification in the Lung, Thymus and Genitourinary Tract}

The nomenclature of pulmonary and thymic NENs differs from GEP-NENs. For these primary localizations, the term carcinoid is still in use. Carcinoids are distinguished from poorly differentiated NECs. Carcinoids correspond to well-differentiated NETs and are composed of bland, monomorphic cells. They show so-called differentiated growth patterns as in GEP-NETs. They are further subdivided according to the WHO classification (2004) into typical (TC) and atypical (AC) carcinoids; these groups show many similarities to G1 and G2 GEP-NETs, although they are not identical.

\section{Typical Carcinoid}

Carcinoid tumors share the same morphological criteria as well-differentiated NETs in other organ sites. Macroscopically, they are well-demarcated, tan to yellow tumors, often associated with bronchial mucosa. The histological diagnosis is based 
on their cytological criteria and growth pattern. Monomorphic tumor cells with round to oval nuclei, finely dispersed chromatin and a moderate amount of eosinophilic cytoplasm are characteristic. The neoplastic cells often grow in a nested, trabecular or solid fashion. TC by definition have less than 2 mitoses per $2 \mathrm{~mm}^{2}$ and no necrosis.

\section{Atypical Carcinoid}

By definition, AC have 2-10 mitoses per $2 \mathrm{~mm}^{2}$ or necrosis. The necrotic areas are usually punctate. The morphological growth pattern and cytology are identical to TC.

\section{Poorly Differentiated NECs}

Pulmonary, thymic and urogenital NECs have more than 10 mitoses per $2 \mathrm{~mm}^{2}$, although in most cases they exceed this number by far and show more than 50 mitoses per $2 \mathrm{~mm}^{2}$. They do not show the differentiated growth patterns of NETs, but instead have a solid or sheet-like growth and frequently exhibit geographic necrosis. Also, for pulmonary NECs, a further subdivision into small and large cell variants corresponding to their nuclear size is recommended, with small cell variants having a cell size corresponding to less than three lymphocytes. Evaluation of the Ki-67 proliferative activity by MIB1 staining, which is an integral part of the assessment in GEP-NETs is, at least to date, not compulsory, although it seems to bear additional prognostic implications [19].

\section{TNM Staging System}

Pulmonary NENs are classified according to the 7th edition of the UICC/AJCC [6] as lung cancer, even if the prognostic value of this system has never been proven useful for NENs. Currently, there is also no specific TNM staging system for thymic and urogenital NENs.

\section{Immunohistochemistry}

Immunohistochemical Markers to Confirm Neuroendocrine Differentiation

Depending on the site of the tumor and the guideline used, immunohistochemistry is useful/mandatory to confirm the neuroendocrine differentiation. Today the most commonly used markers are synaptophysin and chromogranin A, which both have a cytoplasmic staining pattern. Chromogranin A is a component of large secretory granules. Its expression level depends on the number of secretory granules [20]; therefore, poorly differentiated NECs often show only focal staining or even a lack immunohistochemical positivity for chromogranin A [21].

Synaptophysin is a membrane protein of small vesicles of neuroendocrine cells [22]. It has a lower specificity but a higher sensitivity for neuroendocrine differ- 
entiation in comparison to chromogranin A. It is more likely to be preserved in poorly differentiated NENs.

Beyond this, neuron-specific enolase, CD56/NCAM and PGP9.5 are additional markers of neuroendocrine differentiation. Due to their lack of specificity their use is not recommended anymore [21].

\section{Immunohistochemical Markers to Indicate the Primary Site}

In the case of metastases, it is a challenge to identify the origin of the primary tumor on morphological grounds alone. A few markers have been shown to provide information regarding the primary site in such circumstances. They encompass either peptide hormones, enzymes involved in their biogenesis or transcription factors.

The vesicular monoamine transporter 2 (VMAT2) is expressed in gastric NENs [10]. A positive staining for serotonin suggests primarily an ileal origin, but can also be found in NETs from the jejunum or appendix and less frequently from other sites, such as the lung or pancreas [21]. Expression of somatostatin and gastrin points towards a duodenal or pancreatic primary. Cytoplasmic staining for NESP-55 (neuroendocrine secretory protein-55) seems to be restricted to tumors of pancreatic (or adrenal) origin [23], and the immunohistochemical expression of insulin, glucagon and pancreatic polypeptide points towards a pancreatic primary.

The transcription factor CDX2 is expressed in intestinal NETs. Nuclear staining for islet 1 strongly suggests a pancreatic origin [24]. Conflicting results have been published concerning the reliability of thyroid transcription factor 1 (TTF-1) for pulmonary NETs. Although a subset of carcinoids expresses this marker, there are other NETs, including medullary thyroid carcinoma, which express TTF-1. Therefore, immunohistochemical results must be interpreted with caution [24, 25]. Interestingly, $80-100 \%$ of rectal NETs express prostate-specific acid or prostate-specific acid phosphatase [26].

While all the above markers are of use in well-differentiated NETs, this is not the case for poorly differentiated NECs [27]. Immunohistochemistry here can be of help in the differential diagnosis between Merkel cell carcinomas and cutaneous metastases of pulmonary NECs: while Merkel cell carcinomas are usually positive for CK20, typically with a dot-like staining pattern, they are normally negative for TTF-1. In contrast, pulmonary NECs should be negative for CK20 and show TTF-1 expression in a proportion of cases.

\section{Immunohistochemical Predictive Markers}

The expression of somatostatin receptors (SSTR) is a typical feature of well-differentiated NENs with high expression levels, especially in tumors of GEP origin. In the absence of a preoperative SSTR imaging, immunohistochemistry is the best way to determine a potential receptor expression. Immunohistochemistry for SSTR subtype 2a has been shown repeatedly to be a reliable method by which to detect high receptor 
Table 2. Discrimination between different types of gastric ECL cell carcinoids

\begin{tabular}{llll}
\hline & Type 1 & Type 2 & Type 3 \\
\hline Gastric mucosa & $\begin{array}{l}\text { Chronic atrophic gastritis } \\
\text { ECL cell hyperplasia } \\
\text { (linear or micronodular) } \\
\text { Multiple tumors }\end{array}$ & $\begin{array}{l}\text { Hyperplasia of parietal cells } \\
\text { ECL cell hyperplasia }\end{array}$ & Normal \\
& Multiple tumors & \\
\hline Grading & G1 & G1-2 & Often G3 \\
\hline
\end{tabular}

expression levels. At least a moderate (noncircumferential) membranous staining [28] in at least $20 \%$ of tumor cells [29] correlates with in vivo SSTR-2 measurement. Markers predicting response to the wide range of therapeutic compounds applied to NENs have not yet been described.

\section{Immunohistochemical Prognostic Markers}

Estimation of the aggressiveness of NENs is a challenge since morphological characteristics, in contrast to other neoplasms, are of limited use. Proliferative activity measured by MIB1 staining has been proven in many studies to correlate with outcome. Beyond this, positive staining for cytokeratin 19 and KIT have been proven to be associated with an adverse outcome in pancreatic NENs [30, 31].

\section{Important Organ-Specific Features}

\section{Gastric NENs}

So-called ECL (enterochromaffin-like) cell carcinoids are the most frequent type of gastric NETs. They share phenotypes with normal ECL cells, such as the expression of VMAT2 [32]. Depending on the genetic and biological setting, three different types of gastric ECL cell carcinoids are defined. Even if the tumor tissue cannot be discriminated morphologically, the prognosis of ECL cell carcinoids and, therefore, the therapeutic approach depends strongly on this context. Examining biopsies of the surrounding nonneoplastic mucosa allows the pathologist to find hints to discriminate the three forms (table 2).

The most frequent form, type $1 \mathrm{ECL}$ cell carcinoid [33], is associated with chronic atrophic gastritis. Hypergastrinemia is a driving factor of tumor development. ECL cell carcinoids are multiple and are accompanied by different stages of preneoplastic ECL cell lesions: linear, micronodular, adenomatoid hyperplasia and microcarcinoid. Recognition of the surrounding chronic atrophic gastritis, together with clinical/laboratory diagnosis of CAG, is diagnostic. The stages of preneoplastic lesions predict the risk of recurrence of type 1 ECL-cell carcinoids after endoscopic resection [34]. Most of these NETs are G1 and T1 (according to 
endoultrasonography), and in such cases therapy guidelines recommend endoscopic resection $[35,36]$.

Type 2 ECL cell carcinoids are associated with Zollinger-Ellison syndrome in the setting of a multiple endocrine neoplasia type 1 (MEN1). This rare variant is associated with hyperplasia of parietal cells in the surrounding gastric mucosa and is clinically more aggressive [35]. Biologically, these tumors have a loss of the wild-type MEN1 allele; however, this is not used for clinical diagnosis.

Type 3 ECL cell carcinoids of the stomach arise de novo and are solitary tumors. Frequently, they are poorly differentiated and show a high Ki-67 index corresponding to NEC G3.

All ECL cell carcinoids are characterized by the expression of VMAT2 [32]. The clinical significance of endocrine product expression, such as ghrelin or serotonin, in gastric NETs is unknown.

\section{Duodenal, Jejunal and Ileal NENs}

The predominant proportion of duodenal NENs are well differentiated with only 1-3\% NECs [35]. Usually, they are small and solitary lesions. In $6 \%$ of cases they are associated with MEN1 and multiple tumors in particular should raise the suspicion of this hereditary condition, whereas the majority of NETs arising in a periampullary localization are associated with neurofibromatosis type 1 [35]. Ampullary NETs are often somatostatin-producing tumors, which characteristically contain psammoma bodies [35].

Jejunal and ileal NENs harbor a relatively high risk for an aggressive clinical course. In most cases, lymph node or distant metastases are present at the time of diagnosis [37]. Jejunal and ileal NENs only rarely arise in a hereditary setting [38].

\section{Appendiceal NENs}

Appendiceal NENs are the second most common neuroendocrine neoplasms, most of them being located at the tip of the appendix and found incidentally during appendectomy for appendicitis. Less than 5\% of appendiceal NENs are MANECs, or socalled goblet cell carcinoids. Tumor cells have a signet-ring cell appearance with intracytoplasmic mucin and compressed nuclei at the periphery. These mixed tumors have been shown to be associated with an adverse clinical outcome compared to stagematched ordinary NETs. Often they diffusely infiltrate into the appendiceal fat and show extensive perineural invasion (see also the section 'Mixed Adenoneuroendocrine Carcinoma') [37, 39].

\section{Colonic and Rectal NENs}

It is important to differentiate between colonic and rectal NENs as these neoplasms differ markedly from each other. The most common localization of colonic NENs is the cecum. They are often associated with adenomas or adenocarcinomas. In most cases of colonic NENs, metastases are present at the time of diagnosis, probably due 
Table 3. Immunohistochemical hormonal markers with typical primary sites

\begin{tabular}{ll}
\hline Protein & Organ \\
\hline Insulin & Pancreas \\
Glucagon & Pancreas \\
Somatostatin & Pancreas/duodenum \\
Gastrin & Duodenum/pancreas \\
Vasoactive intestinal polypeptide & Pancreas \\
Pancreatic polypeptide & Pancreas \\
Serotonin & Small intestine/pancreas \\
Adrenocorticotropic hormone & Pituitary/lung/pancreas \\
Calcitonin & Thyroid/pancreas/small intestine \\
\hline
\end{tabular}

to a long asymptomatic course, and therefore have the worst prognosis among GEPNETs $[24,40]$.

In contrast, rectal NENs are more frequently diagnosed in a localized stage and are associated with a better prognosis. They often lack immunohistochemical expression of chromogranin A, while the expression of synaptophysin is retained [21]. Colonic and rectal NENs are not associated with hereditary disease.

\section{Pancreatic NENs}

Most pancreatic NENs are well-differentiated tumors. The recognizable growth patterns correspond to those seen in well-differentiated NENs. Beyond this, insulinomas often exhibit amyloid deposits, while psammoma bodies are frequently found in somatostatinomas [5].

Hormonal markers (table 3) are available and frequently expressed in pancreatic NETs. Their expression level does not imply information about the functional status. Functional tumors are exclusively defined by clinical symptoms due to inadequate hormonal secretion. Pancreatic NETs with a size $<0.5 \mathrm{~cm}$ are classified as microadenomas. Pancreatic NETs can occur in the context of hereditary disease, with MEN1 being the most common, followed by von Hippel-Lindau disease and tuberous sclerosis [41].

\section{Lung NENs}

In contrast to other primary localizations, poorly differentiated NECs, which account for $20 \%$ of all lung tumors, are much more common than well-differentiated NETs, which represent 2\% [42]. Small cell lung cancer (poorly differentiated NEC of the lung, small cell type) is heavily associated with smoking. Among carcinoids, TC forms are 8- to 10-times more frequent than AC.

A precondition, which has been shown to have the potential to progress to carcinoid tumors, is the so-called diffuse idiopathic pulmonary neuroendocrine cell hyperplasia. This is a very rare condition, which is defined by a diffuse proliferation of neuroendocrine cells, either in a linear or nodular fashion, in an otherwise unremarkable lung. If these aggregates of neuroendocrine cells extend beyond the basal membrane 
they are classified as tumorlets, which, by definition, are $<5 \mathrm{~mm}$ in diameter. If the tumor is $0.5 \mathrm{~cm}$ or larger, it is classified as carcinoid. In $5 \%$ of the cases, carcinoid tumors arise in the context of MEN1 [43].

\section{Thymic NENs}

NETs of the thymus are rare tumors. They may arise in the setting of an inherited MEN1 syndrome. It is important to notice that, by definition, the whole tumor population must display an endocrine phenotype [44]. They are classified analogs to pulmonary NETs and the terms TC and AC are used for the well-differentiated thymic types (see also the section 'Lung NENs'). However, compared to the lung, a larger proportion of thymic NETs are categorized in the group of AC. Like their pulmonary counterparts, poorly differentiated thymic NENs are separated into small cell and large cell NECs.

\section{Genitourinary NENs}

The classification of genitourinary NENs is similar to that of pulmonary NENs. The welldifferentiated forms arise most frequently in the ovary as ovarian carcinoids and can be associated with teratomas. Poorly differentiated NECs are reported in the ovaries and in the uterine cervix and endometrium, as well as in the urinary bladder and prostate.

\section{Merkel Cell Carcinoma}

The histological appearance of Merkel cell carcinomas corresponds to poorly differentiated NECs. Morphologically, Merkel cell carcinoma belongs to the group of small round blue cell tumors, which refers to the small nuclei size with sparse cytoplasm. There is no grading system for Merkel cell carcinomas. Several histopathologic features, such as a diffuse growth pattern, infiltration of the subcutis and pronounced lymphocytic infiltrate have been associated with an adverse outcome [45].

\section{References}

1 Kloppel G: Classification and pathology of gastroenteropancreatic neuroendocrine neoplasms. Endocr Relat Cancer 2011;18(suppl 1):S1-S16.

2 Asa SL: Pancreatic endocrine tumors. Mod Pathol 2011;24(suppl 2):S66-S77.

3 Ligneau B, Lombard-Bohas C, Partensky C, Valette PJ, Calender A, Dumortier J, Gouysse G, Boulez J, Napoleon B, Berger F, Chayvialle JA, Scoazec JY: Cystic endocrine tumors of the pancreas: clinical, radiologic, and histopathologic features in 13 cases. Am J Surg Pathol 2001;25:752-760.

4 Singhi AD, Chu LC, Tatsas AD, Shi C, Ellison TA, Fishman EK, Kawamoto S, Schulick RD, Wolfgang CL, Hruban RH, Edil BH: Cystic pancreatic neuroendocrine tumors: a clinicopathologic study. Am J Surg Pathol 2012;36:1666-1673.
5 DeLellis R, Heitz P, Lloyd R, Eng C: Pathology and Genetics of Tumours of Endocrine Organs. Lyon, IARC Press, 2004.

6 Edge S, Byrd DR, Compton CC, Fritz AG, Greene FL, Trotti A (eds): American Joint Committee on Cancer Staging Manual, ed 7. Springer, New York, 2010.

7 Rindi G, Falconi M, Klersy C, Albarello L, Boninsegna L, Buchler MW, Capella C, Caplin M, Couvelard A, Doglioni C, Delle Fave G, Fischer L, Fusai G, de Herder WW, Jann H, Komminoth P, de Krijger RR, La Rosa S, Luong TV, Pape U, Perren A, Ruszniewski P, Scarpa A, Schmitt A, Solcia E, Wiedenmann B: TNM staging of neoplasms of the endocrine pancreas: results from a large international cohort study. J Natl Cancer Inst 2012;104:764-777. 
8 Klimstra DS: Pathology reporting of neuroendocrine tumors: essential elements for accurate diagnosis, classification, and staging. Semin Oncol 2013;40:23-36.

9 Panzuto F, Boninsegna L, Fazio N, Campana D, Pia Brizzi M, Capurso G, Scarpa A, De Braud F, Dogliotti L, Tomassetti P, Delle Fave G, Falconi M: Metastatic and locally advanced pancreatic endocrine carcinomas: analysis of factors associated with disease progression. J Clin Oncol 2011;29:2372-2377.

10 Anlauf M: Neuroendocrine neoplasms of the gastroenteropancreatic system: pathology and classification. Horm Metab Res 2011;43:825-831.

11 La Rosa S, Marando A, Sessa F, Capella C: Mixed adenoneuroendocrine carcinomas (MANECs) of the gastrointestinal tract: an update. Cancers 2012;4:1130.

12 Rindi G, Kloppel G, Alhman H, Caplin M, Couvelard A, de Herder WW, Erikssson B, Falchetti A, Falconi M, Komminoth P, Korner M, Lopes JM, McNicol AM, Nilsson O, Perren A, Scarpa A, Scoazec JY, Wiedenmann B: TNM staging of foregut (neuro)endocrine tumors: a consensus proposal including a grading system. Virchows Arch 2006;449:395-401.

13 Rindi G, Kloppel G, Couvelard A, Komminoth P, Korner M, Lopes JM, McNicol AM, Nilsson O, Perren A, Scarpa A, Scoazec JY, Wiedenmann B: TNM staging of midgut and hindgut (neuro) endocrine tumors: a consensus proposal including a grading system. Virchows Arch 2007;451:757-762.

14 Ekeblad S, Skogseid B, Dunder K, Oberg K, Eriksson $\mathrm{B}$ : Prognostic factors and survival in 324 patients with pancreatic endocrine tumor treated at a single institution. Clin Cancer Res 2008;14:7798-7803.

15 Fischer L, Kleeff J, Esposito I, Hinz U, Zimmermann A, Friess H, Buchler MW: Clinical outcome and long-term survival in 118 consecutive patients with neuroendocrine tumours of the pancreas. Br J Surg 2008;95:627-635.

16 Pape UF, Jann H, Muller-Nordhorn J, Bockelbrink A, Berndt U, Willich SN, Koch M, Rocken C, Rindi G, Wiedenmann B: Prognostic relevance of a novel TNM classification system for upper gastroenteropancreatic neuroendocrine tumors. Cancer 2008; 113:256-265.

17 La Rosa S, Klersy C, Uccella S, Dainese L, Albarello L, Sonzogni A, Doglioni C, Capella C, Solcia E: Improved histologic and clinicopathologic criteria for prognostic evaluation of pancreatic endocrine tumors. Hum Pathol 2009;40:30-40.

18 Kloppel G, Rindi G, Perren A, Komminoth P, Klimstra DS: The ENETS and AJCC/UICC TNM classifications of the neuroendocrine tumors of the gastrointestinal tract and the pancreas: a statement. Virchows Arch 2010;456:595-597.

19 Pelosi G, Rindi G, Travis WD, Papotti M: Ki-67 antigen in lung neuroendocrine tumors: unraveling a role in clinical practice. J Thorac Oncol 2014;9:273-284.
20 Modlin IM, Oberg K, Chung DC, Jensen RT, de Herder WW, Thakker RV, Caplin M, Delle Fave G, Kaltsas GA, Krenning EP, Moss SF, Nilsson O, Rindi G, Salazar R, Ruszniewski P, Sundin A: Gastroenteropancreatic neuroendocrine tumours. Lancet Oncol 2008;9:61-72.

21 Kloppel G, Couvelard A, Perren A, Komminoth P, McNicol AM, Nilsson O, Scarpa A, Scoazec JY, Wiedenmann B, Papotti M, Rindi G, Plockinger U, et al: ENETS consensus guidelines for the standards of care in neuroendocrine tumors: towards a standardized approach to the diagnosis of gastroenteropancreatic neuroendocrine tumors and their prognostic stratification. Neuroendocrinology 2009;90:162-166.

22 Wiedenmann B, Franke WW, Kuhn C, Moll R, Gould VE: Synaptophysin: a marker protein for neuroendocrine cells and neoplasms. Proc Natl Acad Sci U S A 1986;83:3500-3504.

23 Srivastava A, Padilla O, Fischer-Colbrie R, Tischler AS, Dayal Y: Neuroendocrine secretory protein-55 (NESP-55) expression discriminates pancreatic endocrine tumors and pheochromocytomas from gastrointestinal and pulmonary carcinoids. Am J Surg Pathol 2004;28:1371-1378.

24 Schmitt AM, Riniker F, Anlauf M, Schmid S, Soltermann A, Moch H, Heitz PU, Kloppel G, Komminoth $\mathrm{P}$, Perren A: Islet 1 (Isl1) expression is a reliable marker for pancreatic endocrine tumors and their metastases. Am J Surg Pathol 2008;32:420-425.

25 Cheuk W, Kwan MY, Suster S, Chan JK: Immunostaining for thyroid transcription factor 1 and cytokeratin 20 aids the distinction of small cell carcinoma from Merkel cell carcinoma, but not pulmonary from extrapulmonary small cell carcinomas. Arch Pathol Lab Med 2001;125:228-231.

26 Ramage JK, Goretzki PE, Manfredi R, Komminoth P, Ferone D, Hyrdel R, Kaltsas G, Kelestimur F, Kvols L, Scoazec JY, Garcia MI, Caplin ME, et al: Consensus guidelines for the management of patients with digestive neuroendocrine tumours: well-differentiated colon and rectum tumour/carcinoma. Neuroendocrinology 2008;87:31-39.

27 Agaimy A, Erlenbach-Wunsch K, Konukiewitz B, Schmitt AM, Rieker RJ, Vieth M, Kiesewetter F, Hartmann A, Zamboni G, Perren A, Kloppel G: ISL1 expression is not restricted to pancreatic well-differentiated neuroendocrine neoplasms, but is also commonly found in well and poorly differentiated neuroendocrine neoplasms of extrapancreatic origin. Mod Pathol 2013;26:995-1003.

28 Papotti M, Bongiovanni M, Volante M, Allia E, Landolfi S, Helboe L, Schindler M, Cole SL, Bussolati G: Expression of somatostatin receptor types 1-5 in 81 cases of gastrointestinal and pancreatic endocrine tumors: a correlative immunohistochemical and reverse-transcriptase polymerase chain reaction analysis. Virchows Arch 2002;440:461-475. 
29 Korner M, Waser B, Schonbrunn A, Perren A, Reubi JC: Somatostatin receptor subtype $2 \mathrm{~A}$ immunohistochemistry using a new monoclonal antibody selects tumors suitable for in vivo somatostatin receptor targeting. Am J Surg Pathol 2012;36:242-252.

30 Zhang L, Lohse CM, Dao LN, Smyrk TC: Proposed histopathologic grading system derived from a study of KIT and CK19 expression in pancreatic endocrine neoplasm. Hum Pathol 2011;42:324-331.

31 Schmitt AM, Anlauf M, Rousson V, Schmid S, Kofler A, Riniker F, Bauersfeld J, Barghorn A, ProbstHensch NM, Moch H, Heitz PU, Kloeppel G, Komminoth P, Perren A: WHO 2004 criteria and CK19 are reliable prognostic markers in pancreatic endocrine tumors. Am J Surg Pathol 2007;31:1677-1682.

32 Rindi G, Paolotti D, Fiocca R, Wiedenmann B, Henry JP, Solcia E: Vesicular monoamine transporter 2 as a marker of gastric enterochromaffin-like cell tumors. Virchows Arch 2000;436:217-223.

33 Rindi G, Luinetti O, Cornaggia M, Capella C, Solcia E: Three subtypes of gastric argyrophil carcinoid and the gastric neuroendocrine carcinoma: a clinicopathologic study. Gastroenterology 1993;104:9941006.

34 La Rosa S, Inzani F, Vanoli A, Klersy C, Dainese L, Rindi G, Capella C, Bordi C, Solcia E: Histologic characterization and improved prognostic evaluation of 209 gastric neuroendocrine neoplasms. Hum Pathol 2011;42:1373-1384.

35 Delle Fave G, Kwekkeboom DJ, van Cutsem E, Rindi G, Kos-Kudla B, Knigge U, Sasano H, Tomassetti P, Salazar R, Ruszniewski P, et al: ENETS consensus guidelines for the management of patients with gastroduodenal neoplasms. Neuroendocrinology 2012; 95:74-87.

36 Salazar R, Wiedenmann B, Rindi G, Ruszniewski P: ENETS 2011 consensus guidelines for the management of patients with digestive neuroendocrine tumors: an update. Neuroendocrinology 2012;95:7173.

37 Boudreaux JP, Klimstra DS, Hassan MM, Woltering EA, Jensen RT, Goldsmith SJ, Nutting C, Bushnell DL, Caplin ME, Yao JC, et al: The NANETS consensus guideline for the diagnosis and management of neuroendocrine tumors: well-differentiated neuroendocrine tumors of the jejunum, ileum, appendix, and cecum. Pancreas 2010;39:753-766.
38 Eriksson B, Kloppel G, Krenning E, Ahlman H, Plockinger U, Wiedenmann B, Arnold R, Auernhammer C, Korner M, Rindi G, Wildi S, et al: Consensus guidelines for the management of patients with digestive neuroendocrine tumors: well-differentiated jejunal-ileal tumor/carcinoma. Neuroendocrinology 2008;87:8-19.

39 Plockinger U, Couvelard A, Falconi M, Sundin A, Salazar R, Christ E, de Herder WW, Gross D, Knapp WH, Knigge UP, Kulke MH, Pape UF, et al: Consensus guidelines for the management of patients with digestive neuroendocrine tumours: well-differentiated tumour/carcinoma of the appendix and goblet cell carcinoma. Neuroendocrinology 2008;87:20-30.

40 Caplin M, Sundin A, Nillson O, Baum RP, Klose KJ, Kelestimur F, Plockinger U, Papotti M, Salazar R, Pascher A, et al: ENETS consensus guidelines for the management of patients with digestive neuroendocrine neoplasms: colorectal neuroendocrine neoplasms. Neuroendocrinology 2012;95:88-97.

41 Falconi M, Plockinger U, Kwekkeboom DJ, Manfredi R, Korner M, Kvols L, Pape UF, Ricke J, Goretzki PE, Wildi S, Steinmuller T, Oberg K, Scoazec JY, et al: Well-differentiated pancreatic nonfunctioning tumors/carcinoma. Neuroendocrinology 2006;84: 196-211.

42 Horsch D, Schmid KW, Anlauf M, Darwiche K, Denecke T, Baum RP, Spitzweg C, Grohe C, Presselt N, Stremmel C, Heigener DF, Serke M, Kegel T, Pavel M, Waller CF, Deppermann KM, Arnold R, Huber RM, Weber MM, Hoffmann H: Neuroendocrine tumors of the bronchopulmonary system (typical and atypical carcinoid tumors): current strategies in diagnosis and treatment - conclusions of an expert meeting February 2011 in Weimar, Germany. Oncol Res Treat 2014;37:266-276.

43 Sachithanandan N, Harle RA, Burgess JR: Bronchopulmonary carcinoid in multiple endocrine neoplasia type 1. Cancer 2005;103:509-515.

44 Rosai J, Sobin LH: Histological Typing of Tumours of the Thymus. Berlin, Springer, 1999.

45 Mott RT, Smoller BR, Morgan MB: Merkel cell carcinoma: a clinicopathologic study with prognostic implications. J Cutan Pathol 2004;31:217-223.

\author{
Aurel Perren \\ Institute of Pathology \\ University of Bern \\ Murtenstrasse 31, CH-3010 Bern (Switzerland) \\ E-Mail aurel.perren@pathology.unibe.ch
}

